\section{Distribution of Oxygen in a Vitrinite and its Extraction Products}

A vitrinite (petrographic purity : 99 per cent; analysis (moisture- and ash-free) : $83.9 \mathrm{C} ; 5.5 \mathrm{H}$; $8.0 \mathrm{O} ; 1.4 \mathrm{~N}$ per cent ; 1.2 per cent $\mathrm{S}$ by difference) was extracted with pyridine, the pyridine-soluble part with benzene, and this extract finally with petroleum ether (boiling point $40-60^{\circ}$ C.). The ratio of material to solvent was $10 \mathrm{gm}$./litre in all cases. Each extraction was carried out in boiling solvent of analytical purity, for a period of $24 \mathrm{hr}$. with efficient stirring and under purified nitrogen. Exhaustive extraction was thus achieved at each step. A 25 per cent yield was obtained for the pyridine-soluble fraction, which could itself be extracted with benzene to the extent of 20 per cent. The petroleum ether extract represented 40 per cent of the benzene-soluble part. The former was washed further with sodium carbonate, sodium hydroxide and hydrochloric acid to yield 96 per cent of a 'neutral oil'.

The content of hydroxyl groups in vitrinite and its extraction products was determined as described previously ${ }^{1}$, with the exception of the benzenesoluble fraction and those derived from it, in which it was better to use a method developed for asphaltic bitumens $s^{2}$. The amount of quinone oxygen was measured in the pyridine-soluble and derived fractions by means of an analytical adaptation ${ }^{3}$ of quinone reduction with copper and hydrogen sulphide ${ }^{4}$.

The results are summarized in Table 1 . The first column gives the content of oxygen, determined moisture- and ash-free. In the petroleum ethersoluble fraction and the 'neutral oil' there is no ash, but an accurate determination of moisture according to the standard methods used for coal products was not possible on account of the relative volatility of the samples. Therefore, in these cases the analytical data for total oxygen must be considered as maximum values. In the second column (percentage hydroxyl oxygen) the small value reported for the petroleum ether-soluble fraction could not be determined with accuracy, but is certainly correct as an order of magnitude, as can also be ascertained from the near infra-red absorption at about $1 \cdot 42 \mu$. From the third column (percentage quinone oxygen), it can be seen that the benzene-insoluble fraction is the last in the series to contain quinone oxygen in detectable quantity.

Taking into account that in bituminous coals oxygen is present essentially in the form of hydroxyl groups, quinones, and as 'non-reactive's, the results in column 4 show that 'non-reactive' oxygen, calculated by the difference, $\mathrm{O}_{\text {total }}-\left(\mathrm{O}_{\mathrm{OH}}+\mathrm{O}_{\text {quin. }}\right)$, has a remarkably constant value, of about $2 \cdot 8$ per cent, in all fractions where it follows directly from experimental results. Assuming that this value holds true also for the pyridine-insoluble fraction and for vitrinite itself, their quinone oxygen content can be estimated (see Table 1 , column 3 , results in square brackets). Considering the experimental orrors made, the results obtained fit fairly well in the whole scheme for oxygen distribution in the various fractions.

Trends observed in Table 1 are significant. In each extraction step a disproportionation of hydroxyl groups occurs which favours the insoluble residue. This concentration of polar groups is even more marked with respect to quinones. The above observations can certainly be correlated with the change
Table 1. Distribution of OXYGen In A Vitrinite (83.9 PER CENT CARBoN) AND its EXTRaCtion Products

\begin{tabular}{|c|c|c|c|c|}
\hline Sample & $\begin{array}{c}\text { Percentage } \\
\text { oxygen } \\
\text { (moist.-,ash } \\
\text {-free) }\end{array}$ & $\begin{array}{c}\text { Percent- } \\
\text { age } \\
\text { hydroxyl } \\
\text { oxygen }\end{array}$ & $\begin{array}{l}\text { Percent- } \\
\text { age } \\
\text { quinone } \\
\text { oxygen }\end{array}$ & $\begin{array}{c}\text { Percentage } \\
\text { non-reactive } \\
\text { oxygen (by } \\
\text { difference) }\end{array}$ \\
\hline $\begin{array}{l}\text { Vitrinite } \\
\text { Pyridine-insoluble } \\
\text { Pyridine-soluble } \\
\text { Benzene-insoluble } \\
\text { Benzene-soluble } \\
\text { Petroleum ether- } \\
\text { insoluble } \\
\text { Petroleum ether- } \\
\text { soluble } \\
\text { 'Neutral oil' }\end{array}$ & 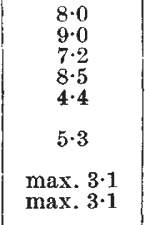 & $\begin{array}{c}4 \cdot 2 \\
4 \cdot 5 \\
3 \cdot 3 \\
3 \cdot 7 \\
1 \cdot 8 \\
2 \cdot 5 \\
(0 \cdot 5) \\
-\end{array}$ & $\begin{array}{c}{[1 \cdot 0]} \\
{[1 \cdot 7]} \\
1 \cdot 0-1 \cdot 2 \\
1 \cdot 6-1 \cdot 8 \\
- \\
-\end{array}$ & $\begin{array}{c}{[2 \cdot 8]} \\
{[2 \cdot 8]} \\
2 \cdot 9-2 \cdot 7 \\
2 \cdot 8-3 \cdot 0 \\
2 \cdot 6\end{array}$ \\
\hline
\end{tabular}

of polarizability in the solvent series. Further, it may be noted that the ratio of hydroxyl to total oxygen remains remarkably constant down to the petroleum ether-insoluble component. On the other hand, the 'non-reactive' oxygen behaves quite differently, since it remains practically constant in amount from the pyridine-soluble extract down to the neutral oil and should be taken into account as a structural parameter ${ }^{6}$.

Experiments have been initiated in this laboratory to investigate the principal nature of this 'nonreactive' oxygen by chemical means. The infra-red spectrum of the neutral oil is sufficiently specific to show clearly a band at $8 \cdot 35 \mu\left(1,198 \mathrm{~cm}^{-1}\right)$ which can be attributed to the antisymmetrical stretching mode of a $\mathrm{C}-\mathrm{O}-\mathrm{C}$ group in which at least one of the carbon atoms is part of an aromatic ring ${ }^{7}$. Thus, making the assumption that the 'non-reactive' oxygen is mainly related to at least partly aromatic ether structures, it seemed worth while to attempt cleavage of these groups with sodium in liquid. ammonia ${ }^{8}$. Results so far obtained on the petroleuminsoluble fraction, the neutral oil, and one of its chromatographic fractions $(2.5$ per cent oxygen) have shown that ether cleavage, indeed, occurs under the conditions of Birch reduction.

The principal change in the infra-red is a new absorption band in the $2 \cdot 9 \mu\left(3,450 \mathrm{~cm} .^{-1}\right)$ region due to -- OH stretching, accompanied by sharply reduced intensity of the $8 \cdot 35 \mu$ band. After acetylation, the reduced samples show no $\mathrm{OH}$ absorption but intense bands at $5 \cdot 69 \mu\left(1,760 \mathrm{~cm}^{-1}\right)$, at $8 \cdot 31 \mu\left(1,205 \mathrm{~cm}^{-1}\right)$ and increased intensity at $7 \cdot 26 \mu\left(1,375 \mathrm{~cm}^{-1}\right)$, which leads to the conclusion that phenolic groups have been acetylated; a further proof that ether oxygen originally present was linked at least on one side to an aromatic system.

The investigation, part of which has been described hore, was supported in this laboratory by the Union Carbide Corporation, New York, to which we are grateful for permission to publish the results.
A. HaLleuX
S. Delavarenne

H. TSCHAMLER

European Research Associates, s.a.,

95 rue Gatti de Gamond, Brussels.

1 Halleux, A., Delavarenne, S., and Tschamler, H., Fuel, 38, 283 (1959). 2 Knotnerus, S., J. Inst. Petrol., 42, 355 (1956).

${ }^{3}$ Delavarenne, S., Halleux, A., and Tschamler, H., Rec. Trav. Chim. Pays-Bas, 80, 27 (1961).

Von, I. U.S. Patent, No, 2,660,580 (Nov, 24, 1953).

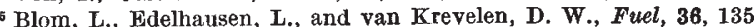
(1957).

Halleux, A., Delavarenne, S., and Tschamler, H., Fuel, 40, 74 (1961).

7 Tschamler, H., and Leutner, R., Monatsh. Chem., 83, 1502 (1952).

8 Birch, A. J., Quart. Rev. Chem., 4, 69 (1950). 